Original Article

\title{
BURDEN OF THERAPY IN PATIENTS SUFFERING FROM DIABETES MELLITUS AND HYPERTENSION
}

\author{
MALI KALPANA RAMANNA ${ }^{1}$, RUCKMANI A. ${ }^{{ }^{*}}$, SIDDHARAM S. JANTI ${ }^{2}$, MADHAVI EERIKE ${ }^{1}$, \\ R. LAKSHMIPATHY PRABU ${ }^{1}$
}

${ }^{1}$ Department of Pharmacology, ${ }^{2}$ Department of Ophthalmology, Chettinad Hospital and Research Institute, Kelambakkam, Kanchipuram
Dt., Tamilnadu 603103 Email: ruckmani.nirmal@gmail.com

Received: 04 Feb 2017 Revised and Accepted: 31 Mar 2017

\section{ABSTRACT}

Objective: To estimate a) monthly expenditure for treatment of diabetes mellitus (DM), hypertension (HTN) and both (DM+HTN) and b) economic burden (EB) and psychological burden (PB) of therapy of DM, HTN and DM+HTN.

Methods: An observational questionnaire-based study was conducted among 180 patients. The monthly cost of drug therapy was assessed based on the drugs they were taking and the cost of individual drugs. The EB and PB were assessed using a validated questionnaire and data analysed by ANOVA followed by post hoc test.

Results: Among 216 patients who were interviewed, 180 fulfilled the selection criteria. Among 180, 75 had DM, 40 HTN and 65 had both Prevalence of DM and DM+HTN was higher among females and of HTN equal among males and females. The average total monthly cost of therapy for DM was INR 2077, for HTN INR 1464 and for DM+HTN INR 2269.

Significant correlation was found between income and percentage of expenditure $(\mathrm{p}<0.001)$ in all the groups. The PB was found to correlate with low income $(\mathrm{p}<0.001)$, poor education $(\mathrm{p}<0.05)$ occupation $(\mathrm{p}<0.01)$ in DM+HTN and number of tablets $(\mathrm{p}<0.01)$ in DM and DM+HTN groups.

Conclusion: The cost of therapy was higher for DM+HTN and DM. The percentage of expenditure was higher in low-income group and burden of therapy was directly proportional to the number of tablets, poor educational and occupational status; and inversely proportional to income.

Keywords: Diabetes, Hypertension, Economic burden, Psychological burden, Cost of therapy, Pharmacoeconomics

(C) 2017 The Authors. Published by Innovare Academic Sciences Pvt Ltd. This is an open access article under the CC BY license (http://creativecommons.org/licenses/by/4.0/) DOI: http://dx.doi.org/10.22159/ijpps.2017v9i5.17484

\section{INTRODUCTION}

Pharmacoeconomics is defined as "description and analysis of the costs of drug therapy to health care systems and society" [1].

Pharmacoeconomic assessment helps to assess the affordability and compare the different treatments which can aid in framing health care policies. The pharmacoeconomic study is important in India as its significant percentage of people live below the poverty line and it is difficult and stressful for them to meet the cost of lifelong treatment of chronic diseases such as DM, HTN, ischemic diseases and others.

Though government institutions provide free treatment, still the time spent on travel to the institute, loss of wages due to travel and expenditure incurred increase the cost of treatment as well as psychological stress for the patients and caretakers. Hence many people use the private sector services. Therefore, it is important to assess how much expenditure is incurred in proportion to the income earned.

The pharmacoeconomic assessment involves comparison of cost and therapeutic outcome. Cost could be direct or indirect or intangible [2, 3].

Direct cost includes both medical and non-medical costs. Medical cost refers to expenditure related to medications, investigations, admissions and management of complications. Non-medical cost includes expenditure on travel, food and other amenities incurred by the patient and the accompanying person/s.

Indirect cost includes loss of wages, premature retirement and productivity loss due to illness.

Intangible cost refers to non-financial outcomes of disease and medical care such as pain and disabilities.
The therapeutic outcome is a consequence of any kind of treatment irrespective of whether the results are expected or unexpected, beneficial or desirable to patients.

The present study focused on the assessment of the direct and indirect cost of the two common coexisting non-communicable diseases, DM+HTN which require lifelong treatment.

Patients suffering from DM+HTN may not be taking only antidiabetic and antihypertensive drugs, but also antacids, multivitamins and hypolipidaemic drugs which can add to the EB.

Drug regimen also becomes complicated when they have to take some drugs before food, some after food and some along with food. Drugs like diuretics should be taken in the morning and statins in the night. Hence it is a burden on the individual to remember the complex regimen adhering to therapy and take all the drugs correctly, which can cause stress and anxiety in the patients. The costs of such lifelong therapy to poor patients increase the anxiety and stress. These factors contribute to PB. Such economic and psychological issues pertaining to antidiabetic and antihypertensive therapies are factored in the present study.

This is the first study that estimates and analyses the combined cost of drug therapy for the most common coexisting diseases, HTN and DM in India, and correlates EB with PB.

\section{MATERIALS AND METHODS}

Study design: prospective observational questionnaire-based study. Study population: outpatients who attended a tertiary care hospital. Study period: Feb 2016 to July 2016. Inclusion criteria: All patients suffering from uncomplicated DM, HTN or both for more than $1 \mathrm{y}$, who were willing to give informed consent. Exclusion criteria: Patients less than $18 \mathrm{y}$ and more than $65 \mathrm{y}$, complicated DM/HTN, 
pregnant women and lactating mothers, patients with associated diseases other than DM and HTN, patients who were not willing to give informed consent and patients who did not have the prescription.

The study was started after obtaining institutional ethics committee approval (IHEC/01/13 Jan 2016/Desp. No-034/11.02.2016). Totally, 216 patients were interviewed. 180 patients fulfilled the selection criteria. Informed consent was obtained and validated questionnaire was given to each participant. The questionnaire was explained to those patients who needed explanation. The questionnaire had 48 questions ( 8 on demographic details, 20 to assess EB and another 20 to assess PB).

20 questions related to EB included the number of drugs taken per day (d), drug name, drug formulation, frequency of administration, total cost of medications, expenditure on admission, cost of travel and meal, the number of days absent from work and approximate loss of wages for both the patient and accompanying person. EB was expressed as a direct cost (medical and non-medical), indirect cost and percentage of income spent on therapy (percentage of expenditure) per month (mo).

Questions for assessment of PB included information on adherence to the regimen, whether patients felt guilty or angry when not taking medication regularly, anxious/depressed about the long duration of therapy, purposeful withdrawal of taking medications due to frustration and disturbance in sleep pattern. PB was assessed using psychological burden score (PBS). To calculate PBS each question was given a score of 1 and the total score was 20 . Patients having<7 scores were considered to have the mild burden, a score between 7 14 moderate and score $>14$ severe burden. The correlation between PBS and income, the percentage of expenditure, the number of drugs, educational status, occupation and gender was evaluated.

\section{Statistical analysis}

Values expressed as percentage, mean, mean \pm SEM. Data were analysed statistically using ANOVA followed by post hoc test.

\section{RESULTS}

Among 180 patients there were 96 females and 84 males. Their age ranged from 20-60 y and educational status from illiterate to postgraduate, the income from INR 3000 to more than INR 40000 per mo and occupation included housewives, daily wagers, IT professionals and other office workers.75 patients had DM, 40 HTN and 65 both DM+HTN. Duration of illness ranged from 1 to $25 \mathrm{y}$. A higher number of patients with DM, HTN as well as both DM+HTN was observed in the age group 40$60 \mathrm{y}$.

There were no patients in the age group of 20-30 y with HTN and $\mathrm{DM}+\mathrm{HTN}$ whereas 4 patients were found to have DM in this age group. The percentage distribution in each group is given in table 1 .

Table 1: Percentage distribution of data in each group

\begin{tabular}{|c|c|c|c|c|}
\hline Category & Subcategory & DM (\% of patients) & HTN (\% of patients) & DM+HTN (\% of patients) \\
\hline \multirow[t]{2}{*}{ Sex } & Male & 44 & 50 & 48 \\
\hline & Female & 56 & 50 & 52 \\
\hline \multirow[t]{4}{*}{ Age (y) } & $20-30$ & 4 & 0 & 0 \\
\hline & $31-40$ & 19 & 20 & 11 \\
\hline & $41-50$ & 32 & 18 & 35 \\
\hline & $51-60$ & 45 & 62 & 54 \\
\hline \multirow[t]{6}{*}{ Educational status } & Illiterate & 13 & 15 & 22 \\
\hline & Primary & 27 & 42 & 26 \\
\hline & Secondary & 19 & 18 & 25 \\
\hline & Higher secondary & 16 & 10 & 13 \\
\hline & Graduate & 17 & 12 & 9 \\
\hline & Postgraduate & 8 & 3 & 5 \\
\hline \multirow[t]{5}{*}{ Income } & $\leq 5000$ & 6 & 13 & 14 \\
\hline & $>5000-10000$ & 33 & 27 & 27 \\
\hline & $>10000-20000$ & 33 & 35 & 20 \\
\hline & $>20000-40000$ & 21 & 20 & 28 \\
\hline & $>40000$ & 7 & 5 & 11 \\
\hline \multirow[t]{4}{*}{ Duration of illness (years) } & $\leq 5$ & 53 & 45 & 51 \\
\hline & $>5-10$ & 28 & 40 & 37 \\
\hline & $>10-20$ & 16 & 12 & 10 \\
\hline & $>20$ & 3 & 3 & 2 \\
\hline
\end{tabular}

$\mathrm{DM}=$ diabetes mellitus, $\mathrm{HTN}=$ hypertension, $\mathrm{DM}+\mathrm{HTN}=$ diabetes mellitus and hypertension. Values expressed as a percentage. $(\mathrm{n}=180)$

\section{Economic burden assessment}

It was observed that the monthly average direct medical cost was the highest, indirect cost the modest and direct non-medical cost the lowest in all the 3 disease groups. Loss of wages was higher among those with
DM and DM+HTN than with HTN alone. The total expenditure was found to be high among patients with DM+HTN. (table 2, fig. 1-3).

The correlation between the percentage of expenditure and income was found to be inversely proportional (fig. 4-6).

Table 2: Cost of therapy for DM, HTN and DM+HTN

\begin{tabular}{|c|c|c|c|}
\hline Cost (INR/month) & DM & HTN & DM+HTN \\
\hline Direct medical cost & 1390 & 1043 & 1611 \\
\hline Direct non-medical cost & 145 & 115 & 135 \\
\hline Total direct cost & 1535 & 1158 & 1746 \\
\hline Indirect cost (loss of wages) & 542 & 306 & 523 \\
\hline Total cost & 2077 & 1464 & 2269 \\
\hline
\end{tabular}

$\mathrm{DM}=$ diabetes dellitus, HTN= hypertension, $\mathrm{DM}+\mathrm{HTN}=$ diabetes mellitus and hypertension, INR= Indian rupee. Values expressed as mean.(n=180) 


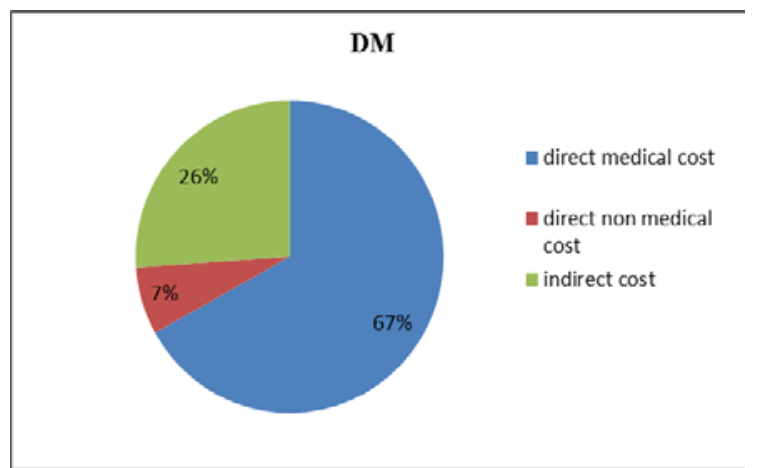

Fig. 1: Percentage distribution of cost of therapy for DM(diabetes mellitus), $(n=75)$

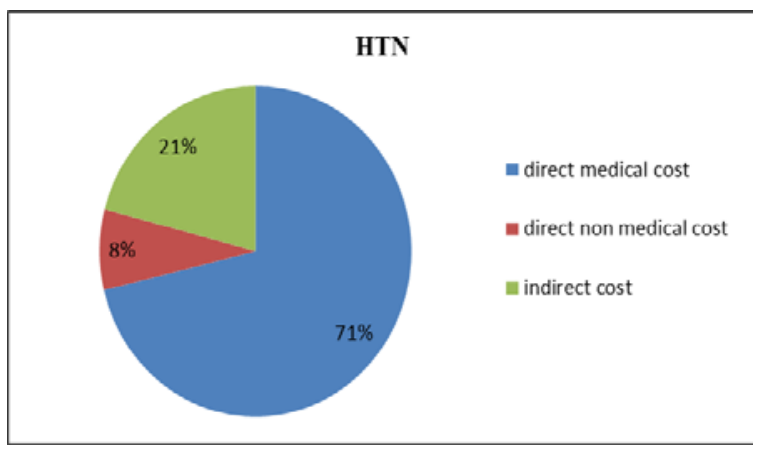

Fig. 2: Percentage distribution of cost of therapy for HTN (hypertension) $(n=40)$

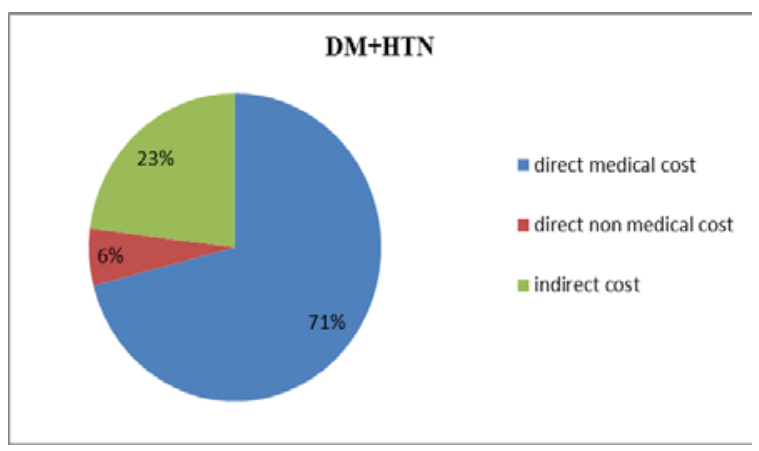

Fig. 3: Percentage distribution of cost of therapy for DM (diabetes mellitus)+HTN (hypertension) $(n=65)$

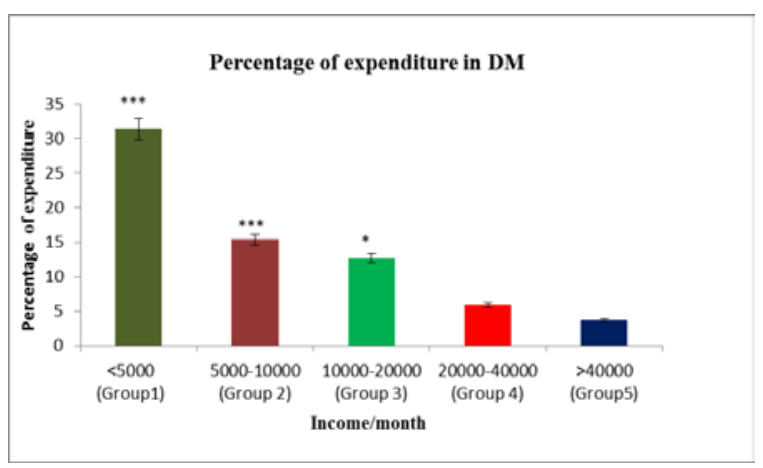

Fig. 4: Income and percentage of expenditure in DM (diabetes mellitus), values expressed as mean \pm SEM. $(n=75)$. Group 1 when compared with group 2, 3, 4 and 5 was found significant $(* * *)<0.001)$. Group 2 when compared with 4 and 5 found significant $(* * *)<0.001)$ and with group 3 not significant. Group 3 when compared with group $4(* \mathbf{p}<0.05)$ and with group 5 not significant

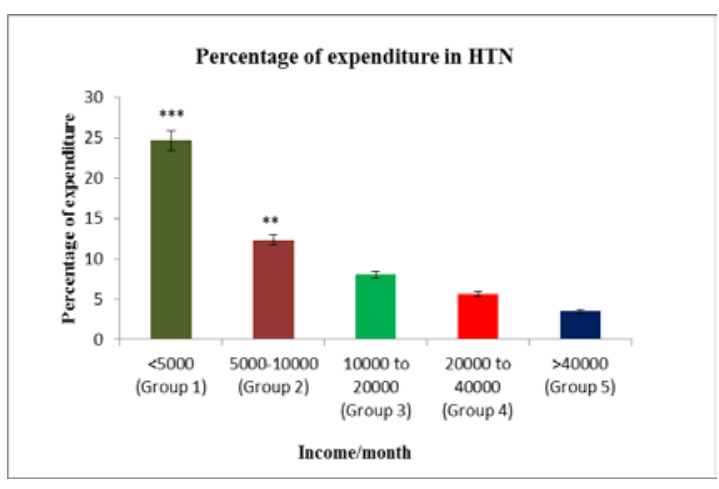

Fig. 5: Income and percentage of expenditure in HTN (hypertension), Values expressed as mean \pm SEM. $(n=40)$. Group 1 compared with groups 2, 3, 4 and 5, was found significant $\left(^{* * *} \mathbf{p}<0.001\right)$. Group 2 compared with groups 3,4 and 5 found significant $\left({ }^{* *} p<0.01\right)$

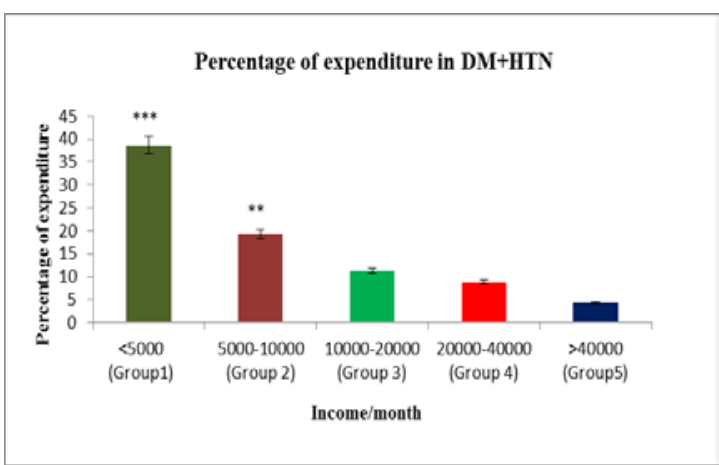

Fig. 6: Income and percentage of expenditurein DM (diabetes mellitus)+HTN (hypertension), Values expressed as mean \pm SEM $(n=65)$. Group 1 compared with groups $2,3,4$ and 5 was found significant $\left({ }^{* * *} p<0.001\right)$. Group 2 compared with groups 3,4 and 5 found significant $\left({ }^{* *} \mathrm{p}<0.01\right)$

\section{Psychological burden}

PB was given a total score of 20 and expressed as a correlation between PBS educational status, occupation, income, the number of drugs, the percentage of expenditure and gender.

Average PBS among three disease groups is depicted in table 3.

The PBS for DM+HTN was higher than that for the individual diseases and all the 3 groups had moderate PB. But the difference observed among the groups was not found to be statistically significant. The correlation between PBS and gender, income, educational status, occupation, the number of drugs and percentage of expenditure is illustrated in (fig. 7-10 and table 4 and 6).

Comparison of gender and PBS showed a higher burden in females than in males among diabetics and diabetics+hypertensives whereas the score was found to be almost equal in females and males among hypertensives. But this correlation was not found to be statistically significant (table 4).

Table 3: Psychological burden score

\begin{tabular}{ll}
\hline Disease category & PBS (total score 20) \\
\hline DM & 7.9 \\
HTN & 8.2 \\
DM+HTN & 9.1 \\
\hline
\end{tabular}

$\mathrm{DM}=$ diabetes mellitus, $\mathrm{HTN}=$ hypertension, $\mathrm{DM}+\mathrm{HTN}=$ diabetes mellitus and hypertension, $\mathrm{PBS}=$ psychological burden score. Values expressed as mean $(n=180)$ 
Table 4: Correlation of PBS and gender

\begin{tabular}{lll}
\hline Diseases & Gender & PBS (total score 20) \\
\hline DM & Females & 8.27 \\
& Males & 7.5 \\
HTN & Females & 8.1 \\
& Males & 8.2 \\
DM+HTN & Females & 9.44 \\
& Males & 8.83 \\
\hline
\end{tabular}

$\mathrm{DM}=$ diabetes mellitus, $\mathrm{HTN}=$ hypertension, $\mathrm{DM}+\mathrm{HTN}=$ diabetes mellitus and hypertension, $\mathrm{PBS}=$ psychological burden score. Values expressed as mean $(n=180)$.

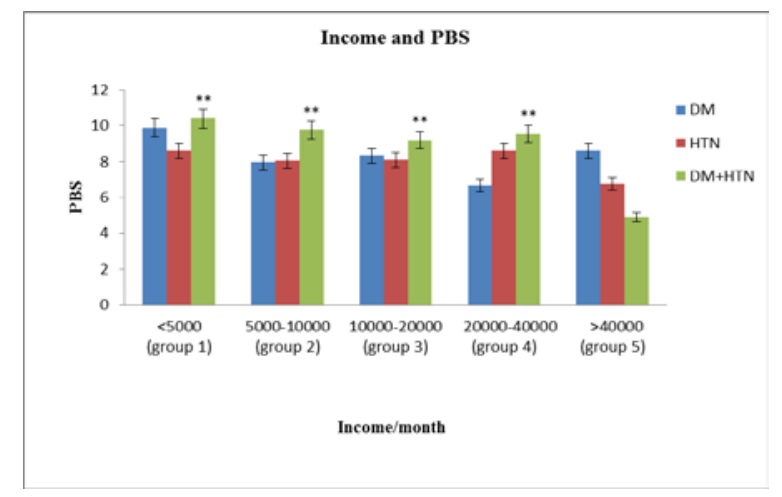

Fig. 7: Income and PBS,DM; diabetes mellitus, HTN; hypertension, DM+HTN; diabetes mellitus and hypertension,

PBS; psychological burden score, Values expressed as mean \pm SEM. $(\mathrm{n}=180) .{ }^{* *} \mathrm{p}<0.01$

The PBS was inversely proportional to income and significant correlation was seen among patients with $D M+H T N(* * p<0.01)$. It was found to be higher in group 1 and lower in group 4 among DM and comparatively lower in group 5 among HTN (fig. 7).

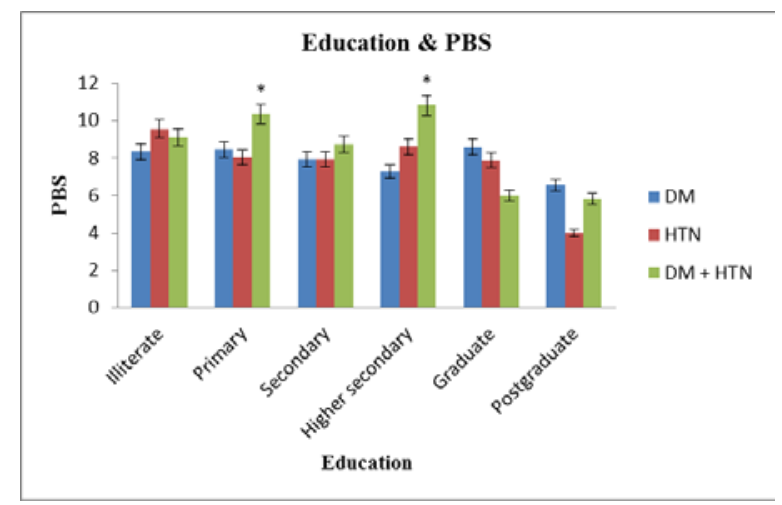

Fig. 8: Education and PBS, DM; diabetes mellitus, HTN; hypertension, DM+HTN; diabetes mellitus and hypertension,

PBS; psychological burden score, Values expressed as mean \pm SEM. $(\mathrm{n}=180) .{ }^{*} \mathrm{p}<0.05$

When PBS was compared with education it was observed that participants with postgraduate degree had lower PBS than others. This correlation was found to be significant among patients with DM+HTN $\left({ }^{*} \mathrm{p}<0.05\right)$ (fig. 8).

The PBS score was found to be higher for IT professionals in DM and HTN groups. The housewives and daily wagers had a higher score in $\mathrm{DM}+\mathrm{HTN}$ group and when IT professionals was compared with housewives $\left({ }^{*} \mathrm{p}<0.05\right)$ and with daily wagers $\left({ }^{* *} \mathrm{p}<0.01\right)$ was found significant in this category (fig. 9).

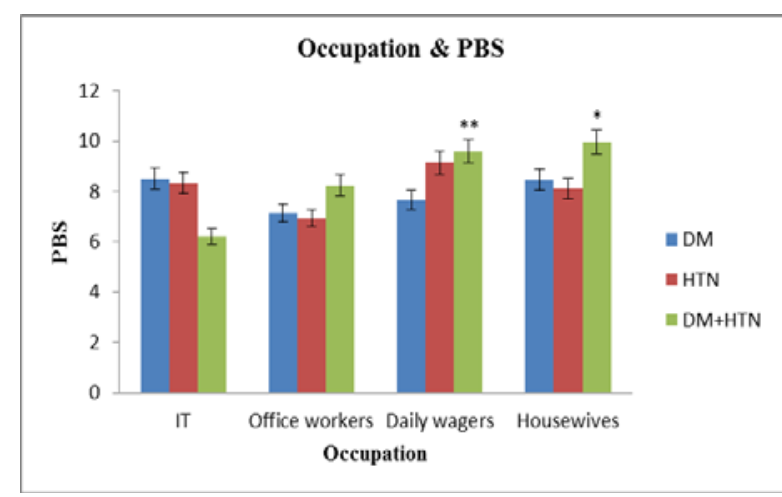

Fig. 9: Occupation and PBS,DM; diabetes mellitus, HTN; hypertension, DM+HTN; diabetes mellitus and hypertension,

PBS; psychological burden score, Values expressed as mean $\pm \operatorname{SEM}(\mathrm{n}=180) .{ }^{*} \mathrm{p}<0.05^{* *} \mathrm{p}<0.01$

The percentage distribution of the number of tablets in each group is shown in table 5.

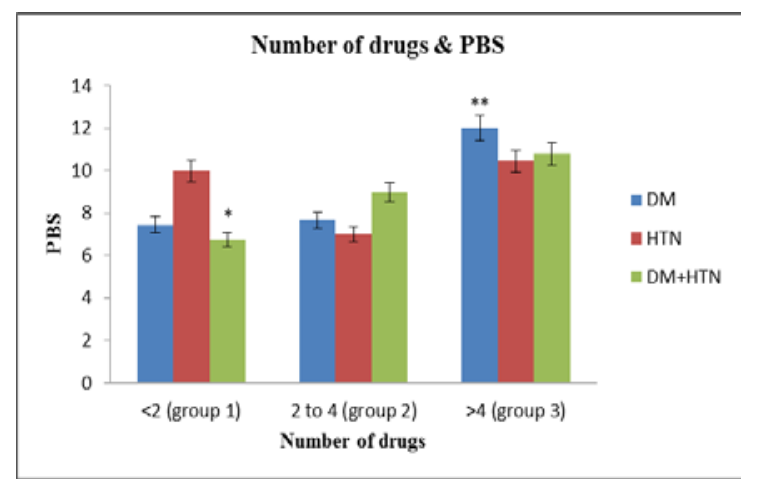

Fig. 10: Number of drugs and PBS, DM; diabetes mellitus, HTN; hypertension, DM+HTN; diabetes mellitus and hypertension,

PBS; psychological burden score, Values expressed as mean \pm SEM $(n=180){ }^{*} \mathbf{p}<0.05^{* *} \mathbf{p}<0.01$

There was a direct correlation between the number of tablets and PBS and found significant among patients with DM $\left({ }^{* *} \mathrm{p}<0.01\right)$ and patients with DM and HTN $\left({ }^{*} \mathrm{p}<0.05\right)$ (fig. 10).

Positive correlation of PBS and percentage of expenditure was seen for DM and HTN whereas for patients who had both DM+HTN such a correlation was not observed. But this correlation was not found to be significant (table 6).

Most of them were taking 2-4 tablets per day. The medications included Metformin, Glimepiride, Voglibose, Insulin, Amlodipine, Atenolol, Telmisartan, Losartan, Enalapril, Pantoprazole, Ranitidine, Atorvastatin, Rosuvastatin and Multivitamins. 
Table 5: Percentage distribution of number of tablets in each group

\begin{tabular}{llll}
\hline Number of tablets/d & DM (\% of patients) & HTN (\% of patients) & DM+HTN (\% of patients) \\
\hline$\leq 2$ & 28 & 3 & 9 \\
$2-4$ & 64 & 65 & 69 \\
$>4$ & 8 & 32 & 22 \\
\hline
\end{tabular}

$\mathrm{DM}=$ diabetes mellitus, $\mathrm{HTN}=$ hypertension, $\mathrm{DM}+\mathrm{HTN}=$ diabetes mellitus and hypertension. Values expressed as percentage (n=180)

Table 6: Correlation of PBS and percentage of expenditure

\begin{tabular}{|c|c|c|}
\hline Diseases & $\%$ of expenditure & PBS \\
\hline \multirow[t]{3}{*}{$\mathrm{DM}$} & $1-20$ & 7.73 \\
\hline & $20-40$ & 8.83 \\
\hline & $40-60$ & 11 \\
\hline \multirow[t]{3}{*}{ HTN } & $1-20$ & 8.1 \\
\hline & $20-40$ & 9.33 \\
\hline & $40-60$ & - \\
\hline \multirow[t]{3}{*}{$\mathrm{DM}+\mathrm{HTN}$} & $1-20$ & 9.17 \\
\hline & $20-40$ & 9.38 \\
\hline & $40-60$ & 9.25 \\
\hline
\end{tabular}

$\mathrm{DM}=$ diabetes mellitus, $\mathrm{HTN}=$ hypertension, $\mathrm{DM}+\mathrm{HTN}=$ diabetes mellitus and hypertension, PBS= psychological burden score. Values expressed as mean $(n=180)$. From the results it was observed that significant correlation was found between income and percentage of expenditure $(* * * p<0.001)$ in all the 3 groups. The PB was found to correlate with low income $\left({ }^{* * *} \mathrm{p}<0.001\right)$, poor education $\left({ }^{*} \mathrm{p}<0.05\right)$ and occupation $\left({ }^{* *} \mathrm{p}<0.01\right)$ in patients with DM+HTN and with number of tablets $\left({ }^{* *} \mathrm{p}<0.01\right)$ in patients with DM and those with DM+HTN.

\section{DISCUSSION}

Due to their high prevalence, DM and HTN were taken up for evaluating the EB and PB of therapy by assessing the cost of medical expenditure, a component of cost of illness.

The highest percentage of expenditure (25-39\%) was seen among the low-income group (INR<5000/per mo) while the lowest (3-4\%) was among the high-income group (INR $>40000 /$ per mo) for all the three disease groups, and this correlation was found statistically significant (fig. 4). When the cost of medication is the same certainly the poor patients spend a high percentage of their income.

In India, there are wider social and economic disparities. Approximately $30 \%$ of the rural population and $26 \%$ of the urban population are below the poverty line [4]. For poor patients, direct cost is met out-of-pocket and money spent on health care is part of family's limited income. Low-income patients do not have enough knowledge; have poor education and lack of awareness of their illness. Poor monitoring of blood pressure and blood glucose and irregular check-up and treatment contribute to the development of complications and finally, the cost of treatment of complications becomes disproportionate to the income which increases the EB.

In the current study total direct cost (INR per mo) for DM was found to be INR 1535. Grover reported that the total cost of DM per capita per mo was INR 828 [5] and Ramachandran et al. reported a higher cost of INR 2005 [6]. Shobhana had compared private hospital INR 4510 and government general hospital INR 246, showing a huge difference between the two. The cost of in treatment in private institution was almost 20 times higher than that in government institutes [7].

In the present study, the indirect cost for DM was found to be INR 542 per mo. The indirect cost of DM per capita per mo estimated by Tharkar was INR 415 [8], closely resembling our study, whereas Bahia et al. have reported a higher cost of INR 4278 [9]. The high cost reported by Bahia could be due to the inclusion of patients with complicated DM and hospitalization for assessment of COI.

The direct cost for HTN in our study was INR 1158 per mo. Nguyen reported INR 3519 for outpatients [10]. The inclusion of complicated HTN with metabolic and lipid storage disorders for assessment of COI would have contributed to the high cost.

The indirect cost for HTN was INR 306 whereas Al-Efan has reported a higher cost of INR 10808, 8903 and 10049 for prehypertension, stage 1 and stage 2 HTN respectively [11]. The inclusion of productivity loss and loss of wages for assessment of indirect cost could have contributed to the huge difference of cost between the two studies.

The direct cost (INR per mo) for DM+HTN was found to be INR 1746 in the current study. The indirect cost for DM+HTN was found to be INR 523 per mo.

There are no COI studies conducted for combined DM+HTN.

Indirect cost was less because this study included only outpatients without complications of the disease. A number of days absent from work and loss of wages may be more for in patients with complicated diseases due to longer duration of hospital stay.

The direct medical cost of all three diseases was found to be higher than direct non-medical and indirect costs. The direct medical cost mainly includes drug cost and admission cost which are expensive, whereas direct non-medical cost includes transportation and meal expenditure on the day(s) of visit to the hospital which is comparatively less expensive. Indirect medical cost includes loss of wages which contributes very less to the total expenditure.

The wide difference observed in the cost of treatment in different studies including the current study may be attributed to the difference in the cost of formulations, the number of tablets, nature of complications, a period of study, place and economic values. But all the studies have concluded that treatments of these diseases were costly and their complication costlier. It is not only a burden to the patient, his/her family, but also to the nation.

Thus the economic assessment has revealed that the poor income group spends more than the higher income group does. The educated spend less than what the illiterate do. The direct cost is higher than the indirect cost for all the 3 groups.

It is natural for any patient to become anxious and stressful when one is informed of her/his chronic ailment such as DM or HTN for which the therapy is lifelong. In addition, these diseases force the patients to adopt a lifestyle with disciplined dietary restrictions. When a patient, who is fond of sweets, is advised to avoid sweets, the disappointment is so great and depressing. Similarly, the dietary restrictions and lifestyle modifications enforced on a hypertensive patient may add to the day-to-day stress one has to cope up with Moreover, when patients have both the diseases, there is not only a need to change lifestyle but also a need to face the challenge of an increase in the cost of therapy. 
One's income is an important factor which decides the regular purchase of medication and the meeting of the cost of interim treatment such as hospitalisation. The burden of treatment will be severe for a person with poor income.

Considering these factors, the current study assessed the treatment burden level and correlated it with the income, percentage of expenditure, number of drugs taken per day, educational and occupational status and gender.

Many of the reported studies have evaluated the stress level using standard stress questionnaires such as perceived stress scale and DM-distress scale developed by Polonski [12].

In this study, the questionnaire was developed incorporating parameters which would assess the ' burden of therapy as perceived by the individual rather than assess the patient's stress. The burden of therapy will be influenced by not only the cost of medications, the number of drugs, frequency of taking these medications, fear resulting from missing a medication and others. This scale was used in this study as it is directly related to medication adherence.

The average PBS was found to be of moderate severity (7.9 to 9.1) in all the three disease groups. Significant differences in the burden level were not observed in our study, among the three groups. This could be because patients with complications and inpatients were not included in the study. Treatment of complications and hospitalisation could increase the expenditure disproportionate to the income, especially for the poor patients, which in turn can increase the stress level.

The PBS was higher among diabetic and diabetic+hypertensive females than among males, whereas burden was equal between hypertensive males and females. In the study done by Sawant et al., [12], statistical significance was seen in the correlation between stress and gender.

When the PBS was compared, it was found to be comparatively lesser for diabetics i.e. 7.9, for hypertensives 8.2 and higher for DM+HTN i.e.9.1. Hence, in this study, patients with both DM and HTN had more burden than patients with either DM or HTN. Awareness that HTN would lead to complications such as myocardial infarction, fear of sudden death or stroke could have contributed to the increased score.

The score was high in patients taking more than 4 tablets for DM and HTN and more than 5 for both DM and HTN whereas low for patients taking 2 or less than 2 tablets for DM and HTN and 3 or less than 3 tablets for both DM and HTN. Hence, more the number of tablets higher the burden level.

The high burden level was observed among illiterate and patients with primary education, whereas low among postgraduates for all 3 diseases.

PB was high for low-income group and low for high-income groups among all the 3 diseases. Correlation of burden score and income among DM+HTN was found significant in our study. Similarly, there was a significant association between stress and monthly income of patient [12].

Percentage of expenditure directly correlated with the burden level among DM and HTN whereas there was no correlation with DM+HTN.

\section{CONCLUSION}

The average total monthly cost of drug therapy for DM, HTN and DM+HTN was INR 2077, INR 1464 and INR 2269 respectively. The EB was closely related to the percentage of expenditure and was higher in a low-income group than in the high-income group. The PB was found to be of mild to moderate severity in both DM and HTN. PB was inversely influenced by educational and economic status and directly proportional to the percentage expenditure and the number of tablets. Women experienced high burden of therapy than men in all the disease groups. Smaller sample size being the limitation of this study, future studies with larger sample size for each group are needed to strengthen such association.

\section{AUTHORS CONTRIBUTION}

Dr. Mali Kalpana Ramanna-Principal Investigator who conducted the study

Dr. Ruckmani A-Contributed to research concept development, topic selection, questionnaire development and guided the research process and manuscript preparation.

Dr. Siddharam S Janti-Participated in data collection

Dr. Madhavi Eerike-Helped in literature review and manuscript writing

Dr. R. Lakshmipathy Prabu-Helped in statistical analysis

\section{ACKNOWLEDGEMENT}

The authors are grateful to Chettinad Hospital and Research Institute for supporting the study.

\section{CONFLICT OF INTERESTS}

All authors declare no conflict of interest

\section{REFERENCES}

1. Parthasarathi G, Nyfort-Hansen K, Nahata MC. A textbook of clinical pharmacy practice-essential concepts and skill. $1^{\text {st }}$ ed. Orient Longman; 2005.

2. Venturini $F$, Johnson KA. Introduction to pharmacoeconomic principles and application in pharmacy practice. Calif J Health Syst Pharm; 2002.

3. William FM, Troy DB, Remington JP. Remington the science and practice of pharmacy. $20^{\text {th }}$ ed. Lippincott Williams and Wilkins; 2000.

4. Rangarajan C. Report of the expert group to review the methodology for measurement of poverty. The government of India planning commission; 2014.

5. Grover S, Avasthi A, Bhansali A, Chakrabarti S, Kulhara P. Cost of ambulatory care of diabetes mellitus: a study from north India. Postgrad Med J 2005;81:391-5.

6. Ramachandran A, Ramachandran S, Snehalatha C, Augustine C, Murugesan $\mathrm{N}$, Viswanathan $\mathrm{V}$, et al. Increasing expenditure on health care incurred by diabetic subjects in a developing country: a study from India. Diabetes Care 2007;30:252-6.

7. Shobhana R, Rao PR, Lavanya A, Williams R, Vijay V, Ramachandran A. Expenditure on health care incurred by diabetic subjects in a developing country-a study from southern India. Diabetes Res Clin Prac 2000;48:37-42.

8. Tharkar S, Devarajan A, Kumpatla S, Viswanathan V. The socioeconomics of diabetes from a developing country: a population-based cost of illness study. Diabetes Res Clin Prac 2010;89:334-40.

9. Bahia LR, Araujo DV, Schaan BD, Dib SA, Negrato CA, Leao MP, et al. The costs of type 2 diabetes mellitus outpatient care in the Brazilian public health system. Value Health 2011;14:137-40.

10. Nguyen TBY, Nguyen TT, Le HH, Schuiling Veninga CCM, Postma MJ. Direct costs of hypertensive patients admitted to hospital in Vietnam'a bottom-up micro-costing analysis. BMC Health Serv Res 2014;14:1.

11. Al-Efan QMA. Cost of treating hypertension in Malaysia. Asian J Pharm Clin Res 2009;2:1-5.

12. Sawant K, Melita S, Castelino F. A study to assess stress and coping among diabetes patients in tertiary health centre of Udupi district Karnataka. Asian Acad Res J Multidis 2014;1:250-60.

\section{How to cite this article}

- Mali Kalpana Ramanna, Ruckmani A, Siddharam S Janti, Madhavi Eerike, R Lakshmipathy Prabu. Burden of therapy in patients suffering from diabetes mellitus and hypertension. Int J Pharm Pharm Sci 2017;9(5):210-215. 